\title{
Stroop-test interference in bipolar disorder
}

Eugenia Kravariti, Katja Schulze, Fergus Kane, Sridevi Kalidindi, Elvira Bramon, Muriel Walshe, Nicolette Marshall, Mei-Hua Hall, Anna Georgiades, Colm McDonald and Robin M. Murray

\begin{abstract}
Summary
We analysed Stroop (neuropsychological screening test) measures of response inhibition in 18 twin pairs discordant for bipolar I disorder compared with 17 healthy control pairs, as well as 40 singletons with bipolar disorder with psychotic features and a family history of psychosis, 46 of their firstdegree relatives without bipolar disorder or psychosis and 48 controls. In both studies, individuals with bipolar disorder showed Stroop deficits and their first-degree relatives
\end{abstract}

showed intact performance. In the twin patients, an interference score was associated with depressive symptoms. Having a first-degree relative with bipolar disorder, even a familial, psychotic form, did not confer risk for enhanced susceptibility to interference in our studies.

\section{Declaration of interest}

None. Funding detailed in Acknowledgements.
A trait-related dysfunction in the ventral prefrontal cortex in bipolar I disorder ${ }^{1,2}$ has been proposed to underlie deficits in the effortful inhibition of pre-potent cognitive responses in favour of less automatic ones. ${ }^{3}$ Response inhibition deficits can be detected using neuropsychological screening tests such as the Stroop ${ }^{4}$ paradigm. Impairment in the latter showed the second largest effect size in relatives of bipolar probands in a recent meta-analysis ${ }^{5}$ showing considerable promise as a candidate endophenotype. However, due to the paucity of relevant studies $(n=4)$, and the substantial heterogeneity of effect sizes $(0.00$ $1.03),{ }^{5}$ this possibility needs further investigation.

We report Stroop findings from a study of twin pairs discordant for bipolar I disorder, and a study of singletons with bipolar disorder and their first-degree relatives without bipolar disorder or psychosis from families multiply affected with psychosis. Of the restricted number of neuropsychological measures that overlapped in the two studies, Stroop was selected for analysis due to its appeal as a candidate endophenotype. ${ }^{5}$ Relatives in both studies were presumed to have enhanced risk for carrying bipolar susceptibility genes owing to increased genetic overlap with an affected proband (56\% of the twin pairs were identical) or to increased familial loading for functional psychosis. We predicted that patients and relatives in each study would show deficits compared with controls and the performance of relatives would fall in-between those of affected probands and controls.

\section{Method}

The two studies were conducted at the Institute of Psychiatry between 1999 and 2007 using non-overlapping samples. Main sources of recruitment were referrals from consultant psychiatrists across the UK, user-led organisations for people affected by bipolar disorder and local/national press advertisements. All participants were characterised diagnostically according to DSM-IV criteria. ${ }^{6}$ Structured diagnostic interviews using the Schedules for Clinical Assessment in Neuropsychiatry ${ }^{7}$ (twin study) and the Schedule for Affective Disorders and Schizophrenia - Lifetime Version ${ }^{8}$ (family study) were performed with all participants. Medical notes were also consulted for most patients. Information regarding psychiatric diagnoses of family members not directly assessed in the family study was obtained from reliable informants using the Family Interview for Genetic Studies ${ }^{9}$ and, when available, from psychiatric notes. All participants were native speakers of English and had no history of neurological disorder, organic brain disease or head trauma resulting in loss of consciousness for more than $10 \mathrm{~min}$. Controls with personal/ family histories of psychotic, bipolar or schizophrenia-spectrum disorders (up to second-degree relatives) were excluded from both studies. The twin study further excluded controls with any lifetime psychiatric diagnoses. No participant was acutely ill at testing (47\% of probands obtained normal-range scores in the Beck Depression Inventory ${ }^{10}(1-9)$ and Altman Self-Rating Mania Scale $\left.^{11}(1-5)\right)$ or had been alcohol or substance dependent over the 12 months preceding assessment (except one co-twin who was alcohol dependent). The Institute of Psychiatry's ethical committee approved both studies.

Eighteen twin pairs discordant for bipolar I disorder and 17 healthy control pairs participated in the twin study. The family study ${ }^{12}$ included 40 patients with bipolar I disorder who had both a history of delusions or hallucinations during illness exacerbation and one or more first- or second-degree relative(s) with bipolar disorder or other functional psychosis. The study further included 46 of the patients' first-degree relatives who had no personal history of psychotic, bipolar or schizophrenia-spectrum disorders, and 48 unrelated control participants. The descriptive characteristics of the studies and the demographic, clinical and neuropsychological characteristics of their respective samples are summarised in online Table DS1.

The Stroop ${ }^{4}$ was administered to all participants, yielding a colour-word score (number correct in the colour-word condition) and an interference score (number correct in the colour condition minus number correct in the colour-word condition). An alternative interference score (colour-word completion time minus colour completion time) was further estimated in the twin study.

In each study, group differences in Stroop scores were investigated in a series of two-step linear regressions for clustered observations, ${ }^{13}$ using robust standard errors to safeguard against potential violations of the standard ANOVA assumptions. In the first step, socio-demographic/IQ variables that had shown significant group differences in separate clustered regressions (twin study: age and IQ; family study: no differences emerged) (online Table DS1) were included in the models. In the second step, affective scores that had shown significant group differences in separate clustered regressions (twin study: depression score; family study: depression and mania scores) (online Table DS1) were further added to the models.

To examine whether controls with lifetime psychiatric diagnoses (family study only) or dizygotic discordant pairs 'diluted' the pattern of findings, all analyses were repeated after excluding both subgroups.

Linear regressions with robust standard errors were used to examine associations between Stroop performance and illness 
duration/affective symptoms in the total patient sample of each study. Age was included as covariate in the twin-study model, because it emerged as a significant predictor of interference score $(P<0.01)$ in the first-step analysis (described above).

\section{Results}

In both studies, significant or trend deficits were detected in the bipolar probands compared with co-twins/first-degree relatives, who were indistinguishable from controls, and in the familystudy/monozygotic probands compared with controls (independent of control sample composition in the family study) (online Table DS1). After covarying for affective symptoms, twin probands (full sample) and monozygotic probands no longer showed trend deficits compared with co-twins/controls, but the remaining differences remained significant or were reduced to trends (online Table DS1). Depression significantly predicted 'colour-word completion time minus colour completion time' in the twin patients (coefficient $=2.82,95 \%$ CI 1.18-4.46, $P=0.002$ ).

\section{Discussion}

We report findings from a twin study, and the largest family study to date, investigating Stroop deficits in bipolar I disorder. The majority of co-twins without bipolar disorder were genetically identical with an affected proband, while the relatives of the family study came from families with multiple occurrences of functional psychosis. Both studies were ideally suited to detect inhibitory control deficits in individuals at presumed enhanced risk for carrying bipolar susceptibility genes. The large sample size, strict statistical control for socio-demographic and intellectual confounders, and combination of two powerful study designs are unique strengths of the present investigation.

Both studies found increased susceptibility to interference in patients with bipolar disorder and intact inhibitory control in their first-degree relatives. The twin study further showed an association between depression and an interference score. Corroborating two earlier studies, ${ }^{14,15}$ these findings do not support our hypothesis that increased susceptibility to interference is an endophenotype for bipolar I disorder.

Most studies of response inhibition in patients with euthymic bipolar disorder ${ }^{16-18}$ and relatives of probands ${ }^{1,15,19}$ have ascertained index cases through specialist clinical settings. A notable difference of our study is its broader source of ascertainment. In addition to the usual routes, affected probands were identified through user-led organisations and press advertisements. It is, therefore, possible that a familial risk for enhanced susceptibility to interference is confined to a subgroup of patients, who are more likely to be found among in-patient and out-patient cohorts. $^{20}$

Our findings do not rule out the possibility that trait-related dysfunction in neural substrates of inhibitory control coexists with intact Stroop performance in individuals at risk for bipolar I disorder. ${ }^{1,2}$

We conclude that being a first-degree relative of an individual with bipolar I disorder, even a severe form with psychotic features and increased familial loading, does not necessarily confer risk for enhanced susceptibility to interference.

\section{Acknowledgements}

E.K. received funding support from the Psychiatry Research Trust. The work was funded by a Guy's \& St Thomas' Charitable Foundation Research Studentship to K.S. M-H.H. received funding support from the Kaplan Fellowship, Harvard Medical School, and the Nationa Alliance for Research on Schizophrenia and Depression (NARSAD) Sidney R. Baer Jr.
Foundation Young Investigator Award. Both C.MCD. and E.B. were Wellcome Trust Fellows. The research project also received support from the Medical Research Council (UK), the Stanley Medical Research Institute and NARSAD. We thank the Manic Depression Fellowship for help with recruitment of participants. We are grateful to all the families who participated in the study.

Eugenia Kravariti, PhD, Katja Schulze, PhD, Fergus Kane, MSc, Sridevi Kalidindi, Eugenia Kravariti, PhD, Katja Schulze, PhD, Fergus Kane, MSC, Sride
MBBS, MRCPsych, Elvira Bramon, MD, PhD, Muriel Walshe, PhD,

MBBS, Nicolette Marshall, PhD, Mei-Hua Hall, PhD, Anna Georgiades, MRCPsych, PhD, Colm McDonald, MRCPsych, PhD, Robin M. Murray, MD, DSC, FRCP, FRCPsych, FMedSci, Department of Psychiatry, NIHR Biomedical Research Centre, South London and Maudsley NHS Foundation Trust, and Institute of Psychiatry, King's College London, UK

Correspondence: Eugenia Kravariti, PhD, Box 58, Institute of Psychiatry, King's College London, De Crespigny Park, London SE5 8AF, UK. Email: e.kravariti@iop.kcl.ac.uk

First received 16 Mar 2008, final revision 14 Aug 2008, accepted 8 Sep 2008

\section{References}

1 Kronhaus DM, Lawrence NS, Williams AM, Frangou S, Brammer MJ, Williams $\mathrm{SCR}$, et al. Stroop performance in bipolar disorder: further evidence for abnormalities in the ventral prefrontal cortex. Bipolar Disord 2006; 8: 28-39.

2 Blumberg HP, Leung HC, Skudlarski P, Lacadie CM, Fredericks CA, Harris BC, et al. A functional magnetic resonance imaging study of bipolar disorder State- and trait-related dysfunction in ventral prefrontal cortices. Arch Gen Psychiatry 2003; 60: 601-9.

3 Frangou $S$, Haldane $M$, Roddy $D$, Kumari V. Evidence for deficit in tasks of ventral, but not dorsal, prefrontal executive function as an endophenotypic marker for bipolar disorder. Biol Psychiatry 2005; 58: 838-9.

4 Trenerry M, Crosson B, DeBoe J, Leber W. The Stroop Neuropsychological Screening Test. Psychological Assessment Resources, 1989.

5 Arts B, Jabben N, Krabbendam L, van OS J. Meta-analyses of cognitive functioning in euthymic bipolar patients and their first-degree relatives. Psychol Med 2008; 38: 771-85.

6 American Psychiatric Association. Diagnostic and Statistical Manual of Mental Disorders (4th edn) (DSM-IV). American Psychiatric Press, 1994

7 Wing JK, Babor T, Brugha T, Burke J, Cooper JE, Giel R, et al. SCAN. Schedules for Clinical Assessment in Neuropsychiatry. Arch Gen Psychiatry 1990; 47: 589-93.

8 Spitzer RL, Endicott J. Schedule for Affective Disorders and Schizophrenia Lifetime Version. New York State Psychiatric Institute, 1978.

9 Maxwell ME. The Family Interview for Genetic Studies Manual. National Institute of Mental Health, 1992.

10 Beck AT, Ward $\mathrm{CH}$, Mendelson M, Mock J, Erbaugh J. An inventory for measuring depression. Arch Gen Psychiatry 1961; 4: 561-71.

11 Altman EG, Hedejer D, Peterson JL, Davis JM. The Altman Self-Rating Mania Scale. Biol Psyciatry 1997; 42: 948-55.

12 Schulze KK, Hall MH, McDonald C, Marshall N, Walshe M, Murray RM, et al. P50 auditory evoked potential suppression in bipolar disorder patients with psychotic features and their unaffected relatives. Biol Psychiatry 2007; 62: 121-8.

13 Williams RL. A note on robust variance estimation for cluster-correlated data. Biometrics 2000; 56: 645-6.

14 Ferrier IN, Chowdhury R, Thompson JM, Watson S, Young AH. Neurocognitive function in unaffected first-degree relatives of patients with bipolar disorder: a preliminary report. Bipolar Disord 2004; 6: 319-22.

15 McIntosh AM, Harrison LK, Forrester K, Lawrie SM, Johnstone EC. Neuropsychological impairments in people with schizophrenia or bipolar disorder and their unaffected relatives. Br J Psychiatry 2005; 186: 378-85.

16 Dixon T, Kravariti E, Frith C, Murray RM, McGuire PK. Effect of symptoms on executive function in bipolar illness. Psychol Med 2004; 34: 811-21.

17 Kerr N, Scott J, Phillips ML. Patterns of attentional deficits and emotional bias in bipolar and major depressive disorder. Br J Clin Psychol 2005; 44: 343-56.

18 Olley AL, Malhi GS, Bachelor J, Cahill CM, Mitchell PB, Berk M. Executive functioning and theory of mind in euthymic bipolar disorder. Bipolar Disord 2005; 7: 43-52.

19 Zalla T, Joyce C, Szoke A, Schurhoff F, Pillon B, Komano O, et al. Executive dysfunctions as potential markers of familial vulnerability to bipolar disorder and schizophrenia. Psychiatry Res 2004; 121: 207-17.

20 Loughland CM, Lewin TJ, Carr VJ, Sheedy J, Harris AW. RBANS neuropsychological profiles within schizophrenia samples recruited from non-clinical settings. Schizophr Res 2007; 89: 232-42. 